\title{
Older urban Black South African women are increasingly at risk of low bone mass and high bone turnover
} Marlena C Kruger ${ }^{1}$, Salome Kruger² Hattie H Wright ${ }^{3}$, WD Schutte ${ }^{4}$, Iolanthé M Kruger ${ }^{5}$.

\section{School of Food and Nutrition, Massey Institute for Food Science and Technology, Massey University, Palmerston North, New Zealand

\section{BACKGROUND:}

Globally, rural to urban migration is accompanied by changes in dietary patterns and life style which have serious health implications, including development of low bone mass. South African studies indicated that urban Black and White women have similar bone turnover. However, urban Black women had low bone mass and greater exposure to lifestyle risk factors for bone disease. This prospective study was part of the South African arm of the "Prospective Urban and Rural Epidemiology study" (PURE).

The purpose of this prospective study was to assess changes in bone turnover, parathyroid hormone (PTH) levels, bone health (forearm, hip and lumbar spine bone mineral density) in urban black South African women over 3 years.

\section{METHODS}

Black, urban postmenopausal women ( $\mathrm{n}=144,>50 \mathrm{yrs})$ from the North-West Province, South Africa were recruited. Forearm bone density measurements (BMDDTX) were performed at the distal and ultra-distal sites in the nondominant arm (DTX-200 Osteometer MediTech).

Conventional central bone density (BMDDXA) scans of the lumbar spine (L1L4) and hip were performed using a Hologic Discovery-W (Hologic, Wisconson, USA). Blood concentrations of C-Telopeptide of Type I collagen (CTx), Parathyroid hormone and $25(\mathrm{OH})$ D3 were assessed (Roche Elecsys) and physical activity (PA) was assessed using a validated questionnaire.

Table 1: Descriptive data for the cohort of 144 Black South African women in 2010 and at follow up in 2012

\begin{tabular}{|c|c|c|c|c|c|c|c|}
\hline Variable & $\mathbf{n}$ & $\begin{array}{c}\text { Mean } \\
2010\end{array}$ & $\begin{array}{c}\text { SD } \\
2010\end{array}$ & $\begin{array}{c}\text { Mean } \\
2012\end{array}$ & $\begin{array}{c}\text { SD } \\
2012\end{array}$ & $\mathbf{p}^{*}$ & $r^{*}$ \\
\hline Age & 144 & 60.8 & 8.8 & 63.1 & 8.9 & $<.001$ & 0.93 \\
\hline Weight & 144 & 68.3 & 17.9 & 68.5 & 18.1 & 0.67 & 0.03 \\
\hline BMI & 144 & 28.3 & 7.1 & 28.2 & 7.1 & 0.82 & 0.02 \\
\hline Waist Circ. & 141 & 86 & 13.3 & 87.2 & 13.8 & 0.06 & 0.16 \\
\hline CRP & 138 & 8.4 & 11.6 & 7.5 & 10.1 & 0.32 & 0.08 \\
\hline CTX & 132 & 0.52 & 0.27 & 0.6 & 0.32 & $<.005$ & 0.25 \\
\hline PTH & 132 & 45.8 & 25.2 & 53.5 & 28 & $<.001$ & 0.3 \\
\hline Osteo_BMD & 134 & 0.42 & 0.1 & 0.39 & 0.14 & $<.001$ & 0.3 \\
\hline Spine BMD & 143 & 0.84 & 0.15 & 0.83 & 0.15 & 0.09 & 0.14 \\
\hline L Hip BMD & 142 & 0.83 & 0.14 & 0.81 & 0.14 & $<.001$ & 0.38 \\
\hline $25(\mathrm{OH}) \mathrm{D} 3$ & 132 & 37 & 12.9 & 30 & 10 & $<.001$ & 0.55 \\
\hline Mg Intake & 141 & 400 & 165 & - & - & - & - \\
\hline
\end{tabular}

${ }^{*} p$ represents the significance of the dependent $t$-test for the difference between the 2010 and 2012 value.

\# $r$ represents the effect size of the difference.

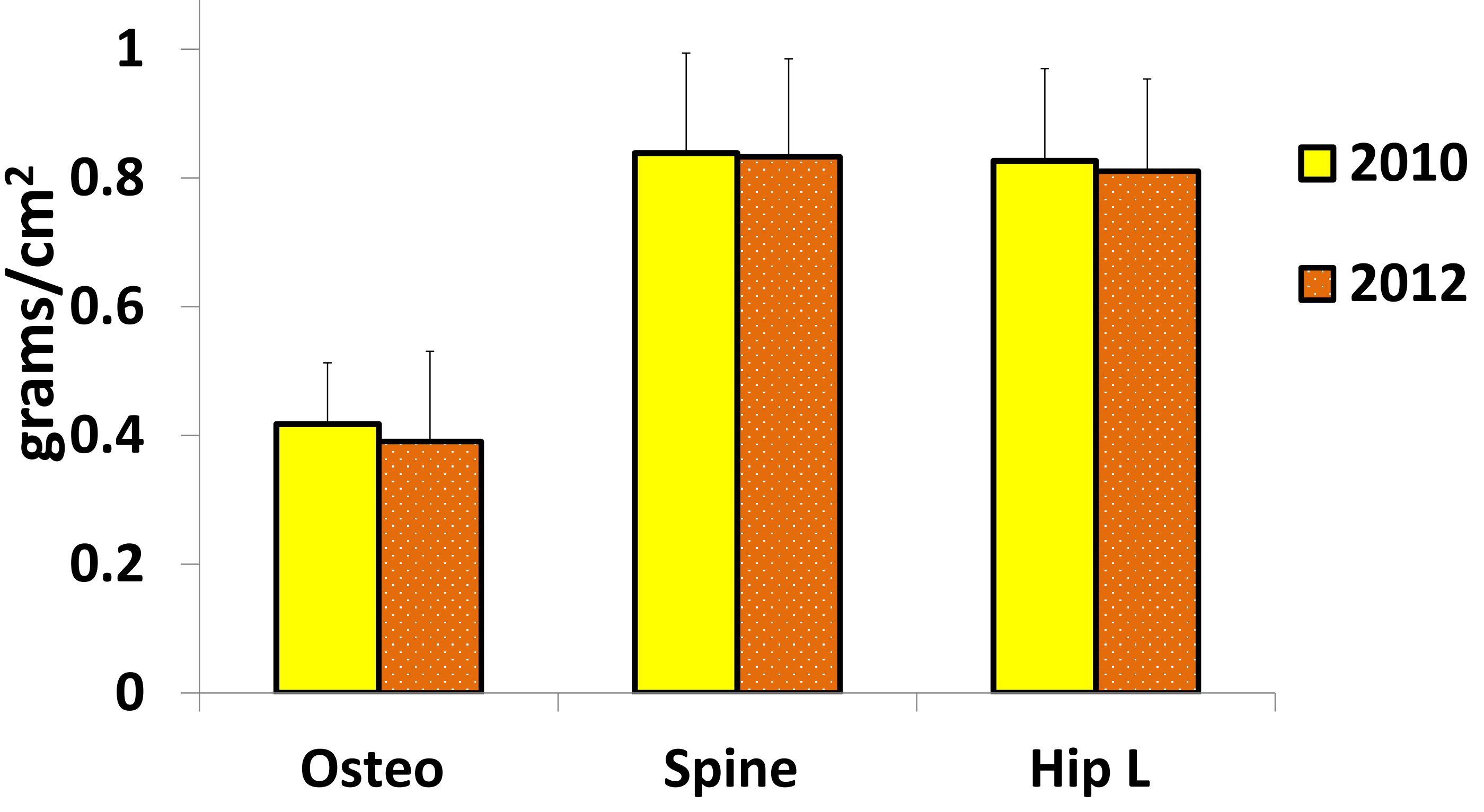

Figure 1:: Changes in bone density over two years as measured using the Osteometer DTX 200 and DXA.. Both Osteo and Left Hip differences were significant and had a medium effect.

\section{ACKNOWLEDGEMENTS}

This study was funded by South African Medical Research Council nr 01.67801.2.RM77005. South African Sugar Association; South Africa Netherlands Research Programme on Alternatives in Development

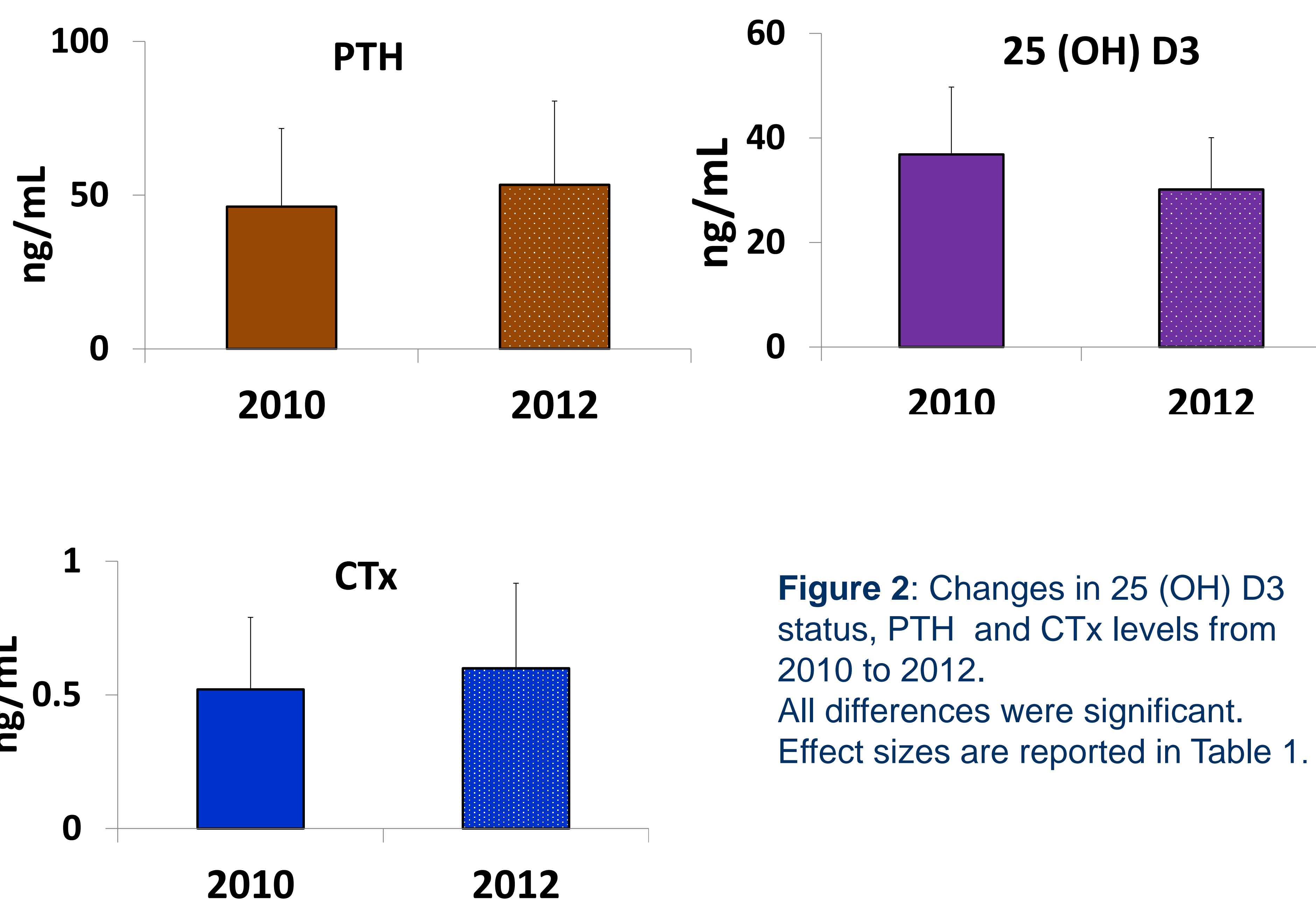

Table 2: Regression results when modelling \% change in CTx as dependent variable.

\begin{tabular}{|c|c|c|c|c|}
\hline & & B & SE B & St Beta \\
\hline \multicolumn{5}{|l|}{ Step 1} \\
\hline & Constant & 0.989 & 0.14 & \\
\hline & $\begin{array}{l}\text { CTx } \\
\text { Baseline } \\
(\mathrm{ng} / \mathrm{ml}) \\
\end{array}$ & -1.274 & 0.236 & $-0.434^{*}$ \\
\hline \multicolumn{5}{|l|}{ Step 2} \\
\hline & Constant & 1.528 & 0.212 & \\
\hline & $\begin{array}{l}\text { CTx } \\
\text { Baseline } \\
(\mathrm{ng} / \mathrm{ml})\end{array}$ & -1.362 & 0.229 & $-0.464^{*}$ \\
\hline & $\begin{array}{l}\text { Magnesium } \\
\text { intake } \\
\text { Baseline }\end{array}$ & -0.001 & 0 & $-0.256^{*}$ \\
\hline
\end{tabular}

Note: $\mathrm{R}^{2}=.188$ for Step 1 , change in $\mathrm{R}^{2}=.065$ for

Step $2(p=.001) .{ }^{*} p<.001$

\section{RESULTS AND CONCLUSION}

Over the three years CTx $(p<.005, r=0.25)$ and PTH levels $(p<.001, r=0.3)$ increased, and $25(\mathrm{OH}) \mathrm{D} 3$ levels reduced $(p<.001, r=0.55)$, while hip bone density decreased significantly $(p<.001, r=0.38)$. In multiple regression the predictors of \% change in CTx were CTx levels and magnesium intake at baseline (both variables had a negative association). This model explained $25 \%$ of the variation, and is reported in Table 2 . All model assumptions held. The predictors of \% change in PTH were PTH levels at baseline (negative association) and C-reactive protein (CRP) at baseline (positive association). CRP (positive association) was a significant predictor of \% change in left hip $\mathrm{BMD}$. Higher CRP at baseline was associated with greater \% changes in PTH and hip BMD. In general, inflammation contributed to greater decreases in BMD and increased bone turnover, whereas a higher physical activity score in 2010 was associated with smaller decreases in BMD among these women.

In conclusion, inflammation contributed to decreases in BMD, whereas lower dietary magnesium intake in 2010 was associated with higher bone turnover after two years. 